\title{
Injecting insulin through clothing was safe and convenient
}

\author{
Fleming DR, Jacober SJ, Vandenberg MA, et al. The safety of injecting insulin through clothing. Diabetes Care 1997 Mar;20:244-7.
}

\section{Objective}

To assess the safety and convenience of injecting insulin through clothing.

\section{Design}

20 week randomised cross over trial.

\section{Setting}

University hospital diabetes clinic in Detroit, Michigan, USA.

\section{Patients}

50 patients who had type I or type II diabetes and had been injecting insulin for $\geqslant 1$ year. 42 patients $(84 \%)$ (mean age $41 \mathrm{y}$, $50 \%$ women, $78 \%$ type I diabetes, $50 \%$ attended $\geqslant 16$ y formal education) with a mean duration of diabetes of 14 years completed the study.

\section{Intervention}

Patients were allocated to a method of injecting insulin through clothing or to the conventional method in which the skin had to be wiped with alcohol and allowed to dry before injecting the insulin. Patients proceeded with their allocated injection method for 10 weeks and then switched to the alternate method for another 10 weeks. Injections through clothing could only be done through 1 layer of fabric; a written list of fabric options was provided. Patients received no specific instructions about the rotation of injection sites, other than to limit the sites to the thighs. Patients recorded information about injections in daily logs and noted benefits and problems.

\section{Main outcome measures}

Leucocyte count, differential count, and glycated haemoglobin concentrations were compared at baseline, 10 weeks, and 20 weeks. The problems (blood, bruising, pain, and infection) and benefits (saves time, convenient, less noticeable, and less awareness) associated with the 2 methods recorded in the daily logs were compared.

\section{Main results}

The groups did not differ for leucocyte count $(p=0.30)$, neutrophil count $(\mathrm{p}=0.14)$, or glycated haemoglobin concentration $(\mathrm{p}=0.63)$. No patients reported adverse skin reactions. The mean number of recorded problems per day did not differ between groups. A mean of 0.32 problems per day was reported with the conventional method of injection compared with 0.40 problems per day with injections through clothing $(\mathrm{p}=0.19)$. A greater mean number of benefits was recorded with injecting insulin through clothing compared with the conventional method (1.34 v $0, \mathrm{p}<0.01)$. The written comments of participants indicated that injecting insulin through clothing was more convenient and did not increase bleeding or bruising at injection sites.

\section{Conclusion}

Injection of insulin through clothing was as safe as, and more convenient than, the conventional injection technique requiring skin preparation.

Source of funding: not stated.

For article reprint:D R Fleming, Diabetes Program, 4201 St. Antoine, UHC-4H, Detroit, MI 48201, USA.Fax +13139930903

Adapted from an abstract published in Evidence-Based Medicine 1997 Jul-Aug;2:116.

\section{Commentary}

At last we have evidence that what people with insulin treated diabetes have been doing for years, probably out of the sight of physicians and nurses, is neither dangerous nor indicates non-compliance or "rogue" behaviour! As health care providers, we have been giving "textbook advice" to people who must manage the complex disease of diabetes on a daily basis. We have failed to recognise the complexity of diabetes self care and the difficulties of incorporating recommendations into busy daily schedules. ${ }^{1}$ Consequently, we have contributed to patient non-compliance, either through exhorting unrealistic expectations of self care behaviour, or by not providing patients with critical information that they need in order to comply with the health recommendations they receive. ${ }^{2}$

Fleming et al provide convincing evidence that injecting insulin through clothing is more convenient and shows no greater risk of infection or other skin reactions, thus removing a potential barrier to attaining metabolic control. Patients in this study were well educated and usually worked in clean environments such as offices. Questions remain regarding the safety of injecting insulin through clothing for individuals who work in environments such as factories. The authors measured short term risks on a small sample of patients; long term evaluation with a larger sample is warranted. Despite these limitations, the findings of the study will help patients with diabetes incorporate insulin injections unobtrusively into their daily routines and reinforce the need for additional investigations on real life experiences and practices of people with diabetes.

\section{Sharon Brown, RN, PhD \\ Associate Dean, Research School of Nursing \\ University of Texas at Austin Austin, Texas, USA}

1 McNabb WL. Adherence in diabetes: can we define it and can we measure it? Diabetes Care

2 Lawler FH, Viviani N. Patient and physician perspectives regarding treatment of diabetes: compliance with practice guidelines. J Fam Pract 1997;44:369-73. 